\title{
Symbiosis Instead of Competing Demands: A Tale of Two Preventive Services
}

Ann Fam Med 2009;7:iii. DOI: 10.1370/afm.950.

The Annals of Family Medicine encourages readers to develop a learning community of those seeking to improve health care and health through enhanced primary care. You can participate by conducting a RADICAL journal club and sharing the results of your discussions in the Annals online discussion for the featured articles. RADICAL is an acronym for Read, Ask, Discuss, Inquire, Collaborate, Act, and Learn. The word radical also indicates the need to engage diverse participants in thinking critically about important issues affecting primary care and then acting on those discussions. ${ }^{1}$

\section{HOW IT WORKS}

In each issue, the Annals selects an article or articles and provides discussion tips and questions. We encourage you to take a RADICAL approach to these materials and to post a summary of your conversation in our online discussion. (Open the article online and click on

"TRACK Comments: Submit a response.") You can find discussion questions and more information online at: http://www.AnnFamMed.org/AJC/.

\section{CURRENT SELECTION}

\section{Article for Discussion}

Potter MP, Phengrasamy L, Hudes ES, McPhee SJ, Walsh JME. Offering home fecal occult blood tests at flu shot clinics increases colorectal cancer screening rates. Ann Fam Med. 2009;7(1):17-23.

\section{DISCUSSION TIPS}

This clinical trial shows a dramatic effect of adding fecal occult blood testing to flu shot clinics. In addition to critiquing the article, it may be worthwhile to consider how the findings might be reinvented in your practice setting.

\section{DISCUSSION QUESTIONS}

- What question is addressed by the article? How does the question fit with what already is known on this topic?
- How does theory inform the intervention design?

- How strong is the study design for answering the question?

- How do the study methods compare with the CONSORT criteria for clinical trials? ${ }^{2}$ What adjustments in the criteria are necessitated by the randomization of clinic days rather than individuals?

- What is the degree to which can the findings be accounted for by:

1. How participants were selected? The exclusion criteria and drop outs? Are any biases likely to be important?

2. How outcomes were measured?

3. Confounding (false attribution of causality because 2 variables discovered to be associated actually are associated with a 3rd factor)?

4. How information was interpreted?

5. Chance?

- What are the main findings? How large is the effect?

- What do we learn from the secondary analyses of factors associated with variations in screening completion, and from the description of attempts to follow up patients with positive fecal occult blood tests? What factors affect interpretation of these findings that are less an issue with interpreting the main effects of the clinical trial?

- How transportable are the findings to your clinical setting? What factors might affect this transportability?

- What are some next steps for applying the findings or answering other questions that this study raises?

\section{References}

1. Stange KC, Miller WL, McLellan LA, et al. Annals Journal Club: It's time to get RADICAL. Ann Fam Med. 2006;4(3):196-197. http:// annfammed.org/cgi/content/full/4/3/196.

2. CONSORT Group. CONSORT: Consolidated Standards of Reporting Trials. http://www.consort-statement.org/. Accessed Oct 26, 2008. 